RESEARCH ARTICLE

\title{
Clinical and Spirometric Characteristics of Premenstrual Asthma
}

\author{
S Aissani ${ }^{1}{ }^{*}$, I Ararem ${ }^{2}$, H Haouichat ${ }^{3}$, ME Haffaf ${ }^{4}$ and A Zitouni ${ }^{1}$ \\ ${ }^{1}$ Pulmonary Service, Hospital Mohammed Seghir El Nekkache, Algeria \\ ${ }^{2}$ Department of Preventive Medicine, Mohammed Seghir El Nekkache Hospital, Algeria \\ ${ }^{3}$ Liberal Doctor, Former Head of Department of Pneumology, Mohammed Seghir El Nekkache Hospital, \\ Algeria \\ ${ }^{4}$ Department of Nuclear Medicine, Mohammed Seghir El Nekkache Hospital, Algeria
}

*Corresponding author: S Aissani, Pulmonary Service, Hospital Mohammed Seghir El Nekkache, Algeria

\begin{abstract}
Summary
Introduction: Premenstrual asthma (APM) is often confused by the patient and/or doctor with the symptoms of asthma in general. The purpose of our study is to investigate the clinical and spirometric characteristics of APM.
\end{abstract}

Materials and method: Prospective descriptive study from 2011 to 2017, on 95 non-menopausal asthma patients, divided into 2 with and without APM. They benefited on a single menstrual cycle of spirometry during the follicular phase, luteal and premenstrual and cutaneous tests.

Results: APM is found in $42.1 \%$ of cases. It is more common between $16-35$ years old. The main symptom is dyspnea in $97.5 \%$ of cases. Premenstrual syndrome is present in $92.5 \%$ of APM. No relationship was found between the severity of asthma and APM $(P=0.41)$. In contrast, uncontrolled asthma is more common in women with APM (75\%). No difference in the spirometry of the 3 phases of the cycle between the 2 groups. In case of APM, the CV is higher during the luteal and premenstrual phases and the PEF is decreased during the premenstrual phase and this in $60 \%$ of the cases.

Conclusion: The results on a single menstrual cycle reinforce the hypothesis of the role of sex hormones in APM.

\section{Keywords}

Asthma, Woman, Menstrual cycle, Sex hormones

\section{Introduction}

Premenstrual asthma (APM) is defined by the exacerbation of asthma before menstruation [1], requiring fast-acting beta 2 mimetics [2]. Some authors have reported a third diagnostic element is the drop in the DEP of more than $20 \%$ premenstruation [3]. APM is often confused by the patient and/or doctor with the symptoms of asthma in general. The purpose of our study is to investigate the clinical and spiometric characteristics of APM.

\section{Materials and Methods}

It is a prospective descriptive study from 2011 to 2017, on 95 patients with non-menopausal asthma, divided into 2 groups according to the presence or absence of premenstrual asthma (APM). These patients are aged between 16 and 55-years-old. They benefited on a single menstrual cycle, spirometry during the follicular phases (between the $3^{\text {rd }}$ and $5^{\text {th }}$ day), luteal (between the $19^{\text {th }}$ to $21^{\text {st }}$ day) and premenstrual (between the $26^{\text {th }}$ and $28^{\text {th }}$ day). Skin tests were done for the most common allergens. We excluded from this work the comorbidities that can influence asthma such as heart disease. Premenstrual asthma was defined as the onset or worsening of asthma symptoms in the last week before menstruation [4]. The exploitation of the results made use of the software Epidata analysis and epi-info 6.

\section{Results}

Premenstrual asthma was found in 40 patients (42.1\%). It is more common between 16 and 35 years of age (Figure 1 ) with an average age of $34.78 \pm 8.97$ years (Table 1). There was no significant difference in average age between those who have and those who do not have premenstrual asthma (Table 1).

The symptoms of premenstrual asthma are represented almost exclusively by an increase in dyspnea re-

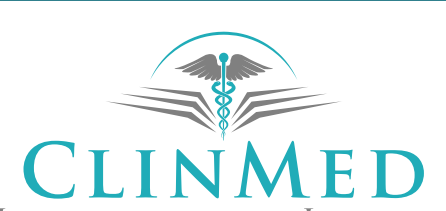

INTERNATIONAL LIBRARY

Citation: Aissani S, Ararem I, Haouichat H, Haffaf ME, Zitouni A (2019) Clinical and Spirometric Characteristics of Premenstrual Asthma. Int J Aller Medications 5:041. doi.org/10.23937/2572-3308.1510041 Accepted: June 04, 2019: Published: June 06, 2019

Copyright: (c) 2019 Aissani S, et al. This is an open-access article distributed under the terms of the Creative Commons Attribution License, which permits unrestricted use, distribution, and reproduction in any medium, provided the original author and source are credited. 


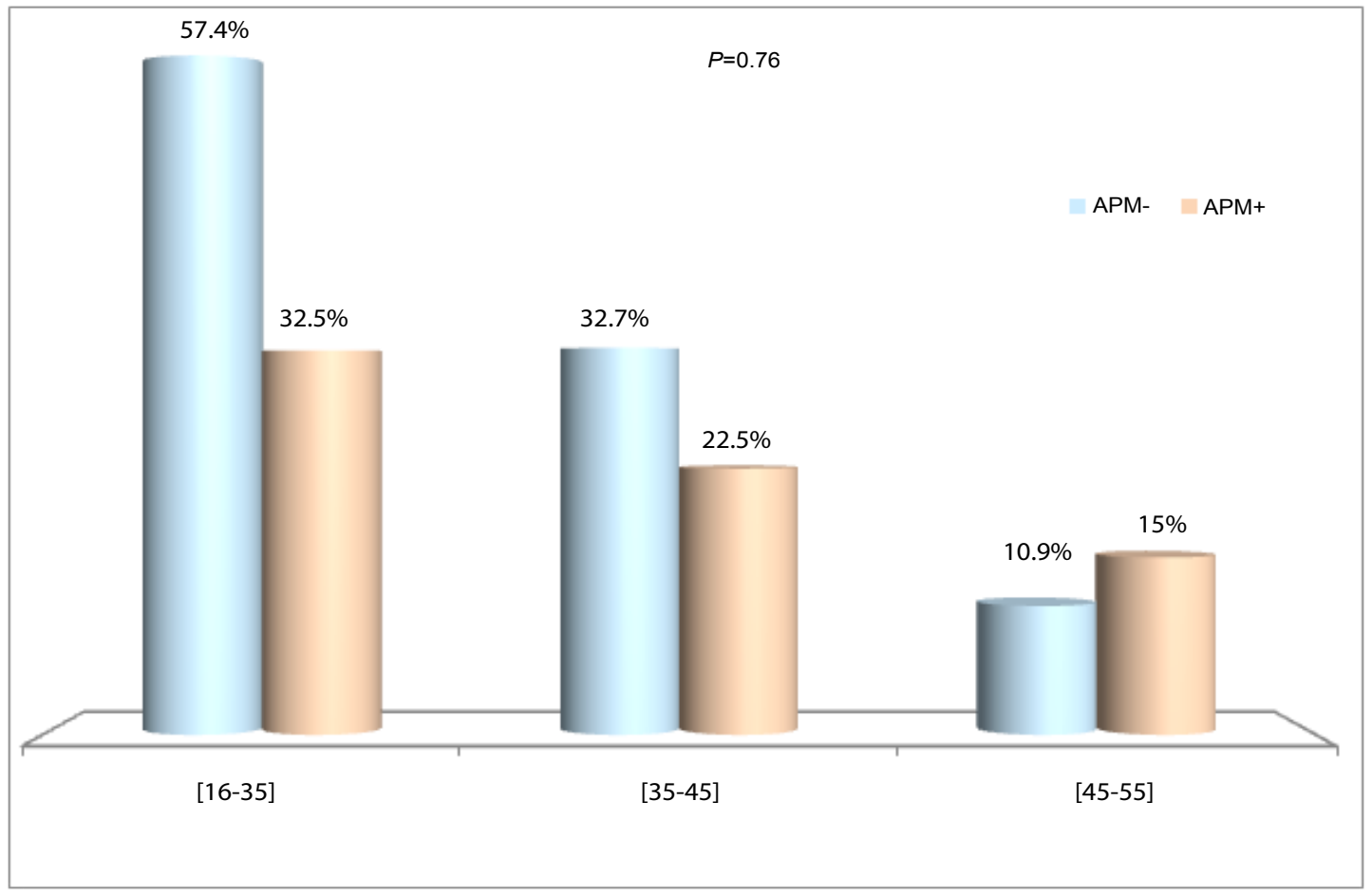

Figure 1: Premenstrual asthma according to age groups.

(APM +: With premenstrual asthma, APM-: Without premenstrual asthma).

Table 1: Clinical characteristics of the two groups.

\begin{tabular}{|c|c|c|c|c|}
\hline & & $A P M-(N=55)$ & $A P M+(N=40)$ & $P$ \\
\hline \multirow[b]{3}{*}{ 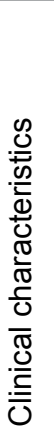 } & Age & $33.11 \pm 9.57$ & $34.78 \pm 8.97$ & 0.39 \\
\hline & Mean BMI $\left(\mathrm{kg} / \mathrm{m}^{2}\right)$ & $26.93 \pm 5.59$ & $26.63 \pm 5.24$ & 0.79 \\
\hline & $\begin{array}{l}\text { BMI }\left(\mathrm{kg} / \mathrm{m}^{2}\right) \\
<18 \\
18-25 \\
25-30 \\
30-35 \\
35-40 \\
>40\end{array}$ & $\begin{array}{l}3(5.5 \%) \\
18(32.7 \%) \\
21(38.2 \%) \\
7(12.7 \%) \\
5(9.1 \%) \\
1(1.8 \%)\end{array}$ & $\begin{array}{l}1(2.5 \%) \\
12(30 \%) \\
20(50 \%) \\
2(5 \%) \\
5(12.5 \%) \\
0\end{array}$ & $\begin{array}{l}0.17 \\
0.32 \\
0.59 \\
0.35 \\
0.83 \\
-\end{array}$ \\
\hline \multicolumn{2}{|c|}{$\begin{array}{l}\text { Physical activity } \\
\text {-low } \\
\text {-Moderate } \\
\text {-intense }\end{array}$} & $\begin{array}{l}18(32.7 \%) \\
4(7.3 \%) \\
-\end{array}$ & $\begin{array}{l}20(40 \%) \\
17(42.5 \%) \\
3(7.5 \%)\end{array}$ & 0.36 \\
\hline \multirow[b]{2}{*}{ 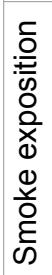 } & Smoke exposure & $16(29.1 \%)$ & $13(32.5 \%)$ & 0.72 \\
\hline & $\begin{array}{l}\text {-Actif } \\
\text {-Passif }\end{array}$ & $\begin{array}{l}1(1.8 \%) \\
14(25.5 \%)\end{array}$ & $\begin{array}{l}1(2.5 \%) \\
13(32.5 \%)\end{array}$ & 0.72 \\
\hline \multicolumn{2}{|c|}{ RGO } & $1(5.5 \%)$ & $3(7.5 \%)$ & 0.68 \\
\hline \multicolumn{2}{|c|}{ Other comorbidities } & $23(41.8 \%)$ & $20(50 \%)$ & 0.42 \\
\hline
\end{tabular}

(APM +: with premenstrual asthma; APM-: without premenstrual asthma).

quiring beta2 mimetics in $97.5 \%$ of cases (Figure 2).

Regarding the number of symptoms in premenstrual asthma, the majority of asthmatics had only dyspnea in 85\% (Figure 3).

Premenstrual syndrome is present in almost all pa- tients with premenstrual asthma (92.5\%). As for premenstrual dysphoric syndrome, it is uncommon. It is found in $16.2 \%$ of cases.

Like premenstrual asthma, premenstrual syndrome is more common in young women under 35 in $56.4 \%$ of 


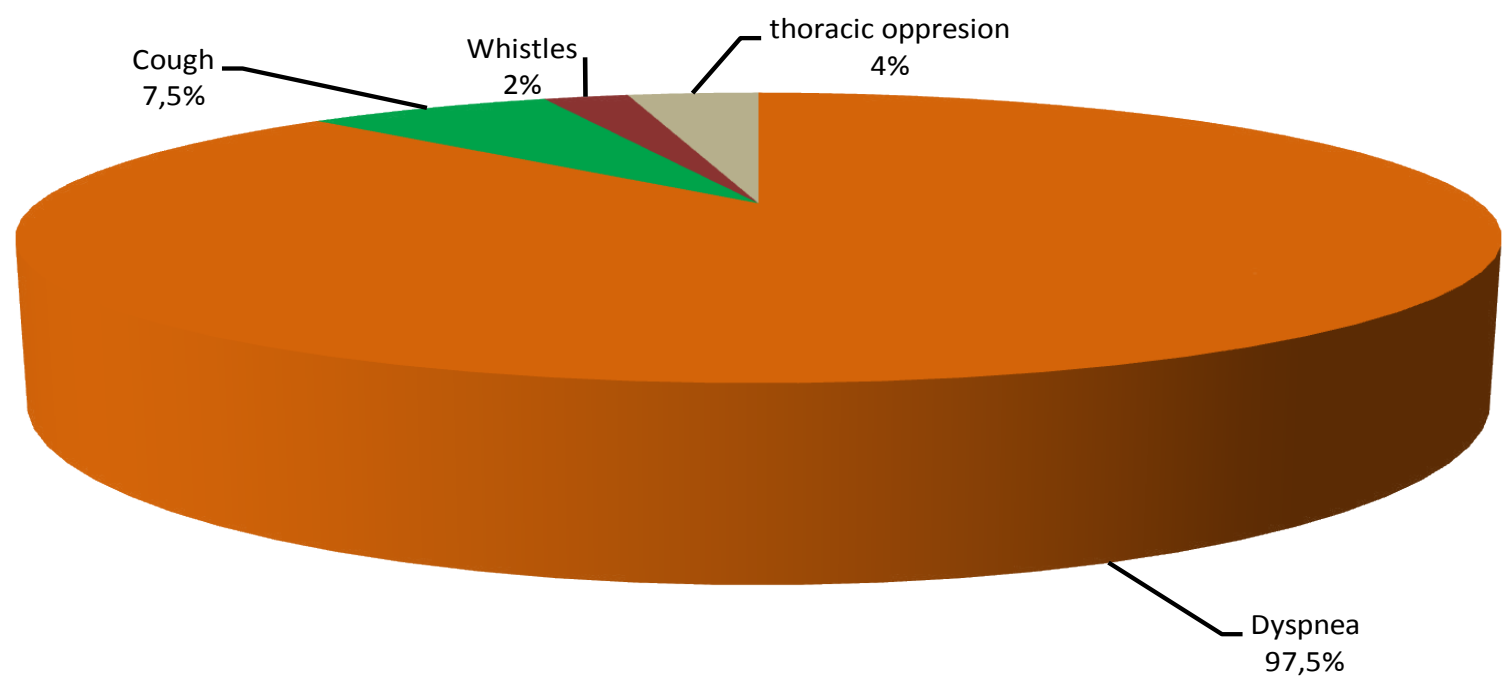

Figure 2: Respiratory Symptoms in premenstrual asthma.

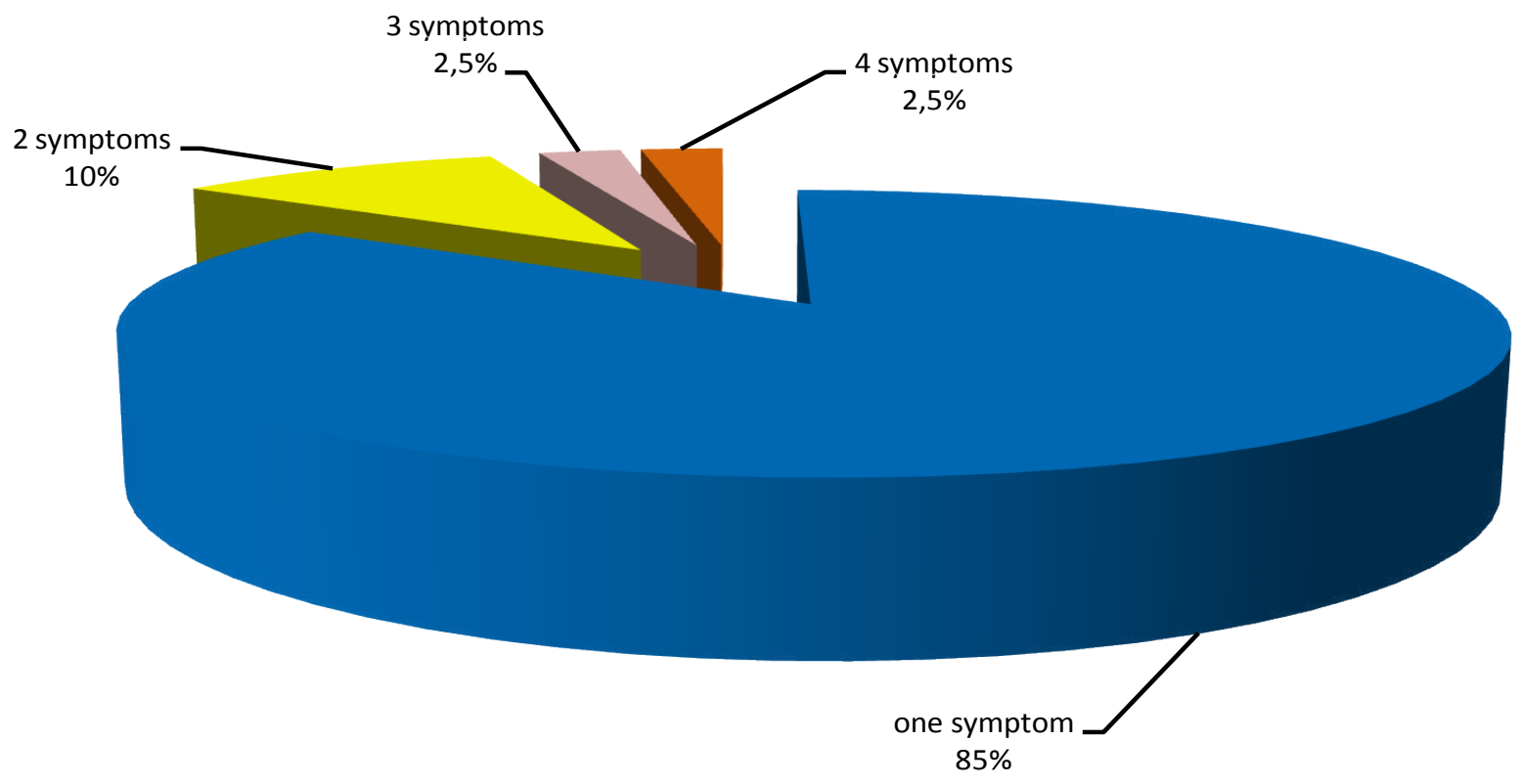

Figure 3: Number of symptôms in premenstrual asthma.

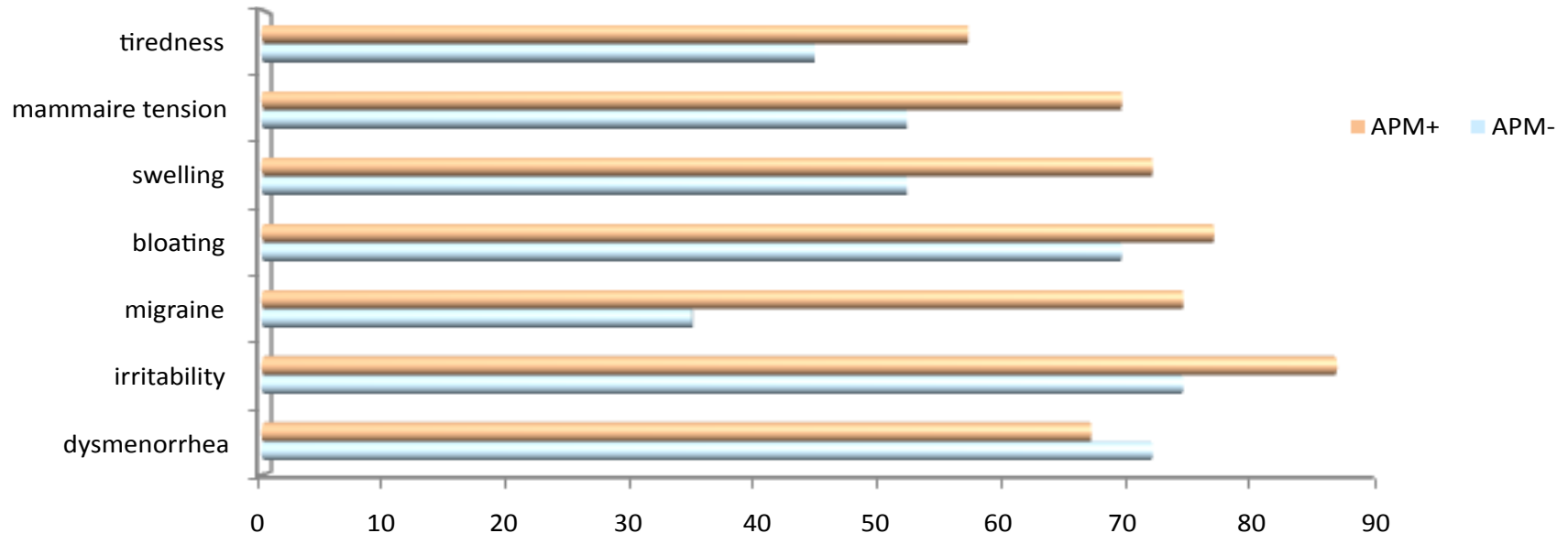

Figure 4: Symptoms fréquency of premenstrual syndrome.

(APM +: with premenstrual asthma, APM-: without premenstrual asthma). 


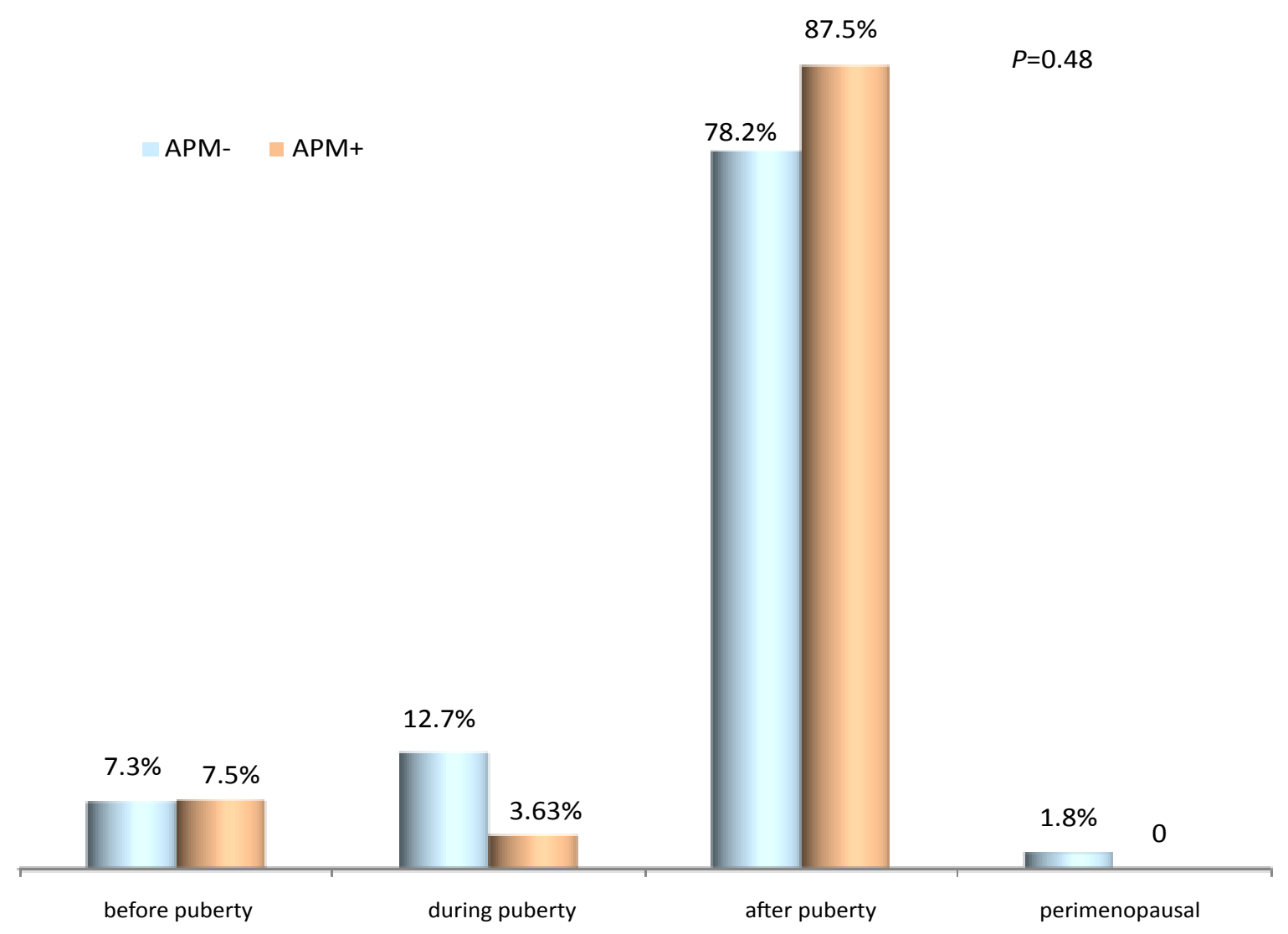

Figure 5: The period of asthma beginning.

(APM +: With premenstrual asthma, APM-: Without premenstrual asthma).

APM- $=$ APM+

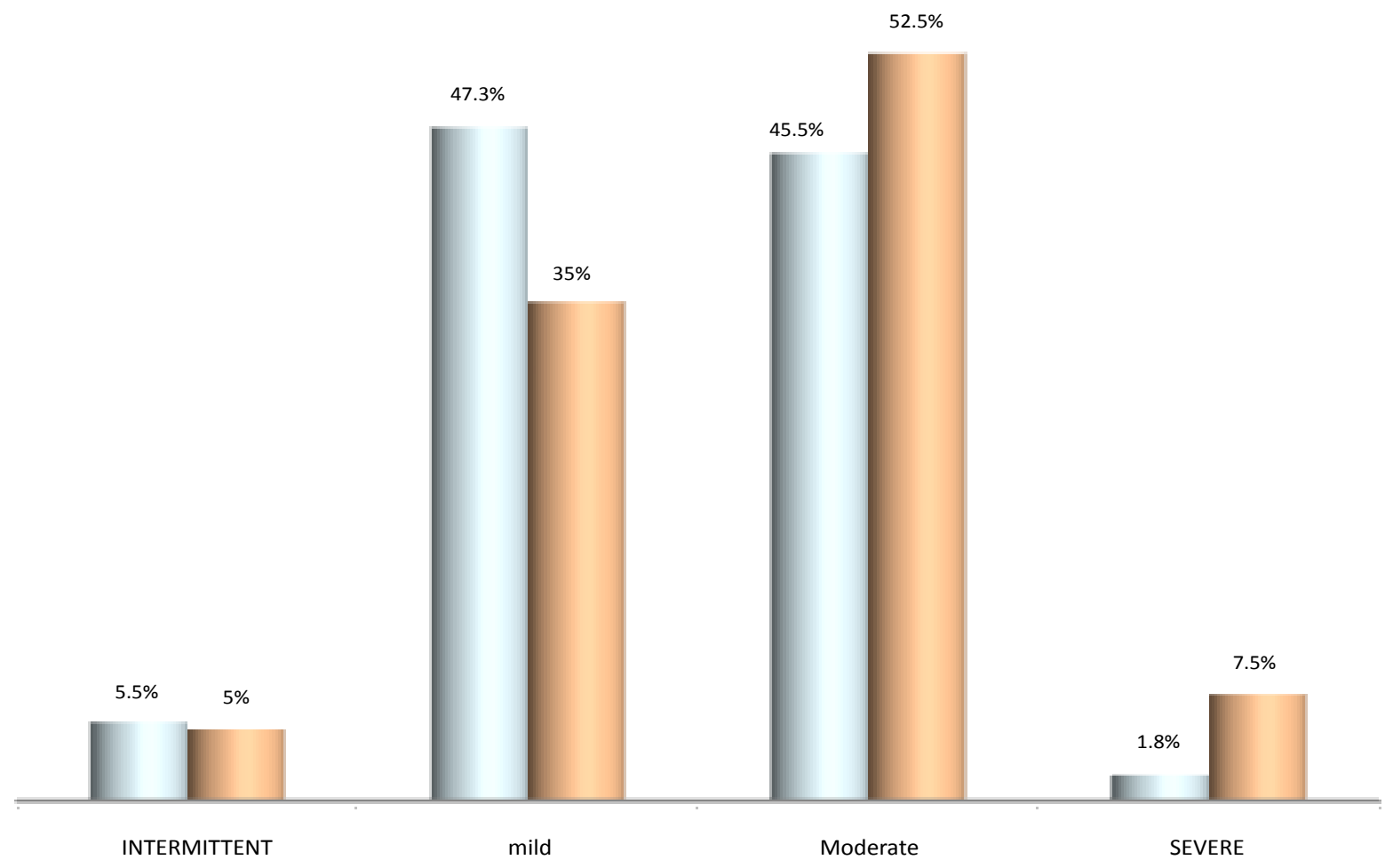

Figure 6: Asthma severity with and without premenstrual asthma. 
cases. Women in the age group [35-45] and those aged 45-55 reported premenstrual symptoms of asthma in $30.7 \%$ and $12.8 \%$ respectively.

All symptoms of premenstrual syndrome are common in premenstrual asthma with headache irritability in $87.5 \%$ of cases (Figure 4).

Women with premenstrual asthma were overweight with an average BMI of $26.63 \pm 5.24 \mathrm{~kg} / \mathrm{m}^{2}$ but no difference with those without premenstrual asthma ( $p=0.39)$ (Table 1).

There was no difference between women with and without premenstrual asthma regarding smoking exposure, co-morbidities and intensity of physical activity (Table 1).

\section{Characteristics of asthma in premenstrual asthma}

- Asthma started after puberty in most women with or without premenstrual asthma (Figure 5).

The duration of asthma is $8.88 \pm 8.85$ years in the presence of premenstrual asthma and is $8.4 \pm 9.05$ years in the absence of premenstrual asthma $(p=0.79)$.
-Asthma severity: Patients with premenstrual asthma have moderate asthma in $52.5 \%$ and mild in $35 \%$ of cases. Severe asthma is uncommon (Figure 6).

\section{Control of asthma in premenstrual asthma}

Uncontrolled asthma was observed in $3 / 4$ of patients with premenstrual asthma and just over $1 / 2$ of patients without premenstrual asthma $(p=0.02)$ (Figure 7).

The concept of familial atopy, the combination of rhinosinusitis and/or other types of skin, food or drug allergies are identical in groups with and without premenstrual asthma. There was no difference in skin test results with or without premenstrual asthma. (Table 2).

In addition, patients with premenstrual asthma have a higher risk of premenstrual syndrome and premenstrual dysphoric syndrome. In addition, they are 4 times more likely to have allergic conjunctivitis (Table 3 ).

\section{Respiratory Functional Exploration in Premen- strual Asthma}

The comparison of spirometers during different phases

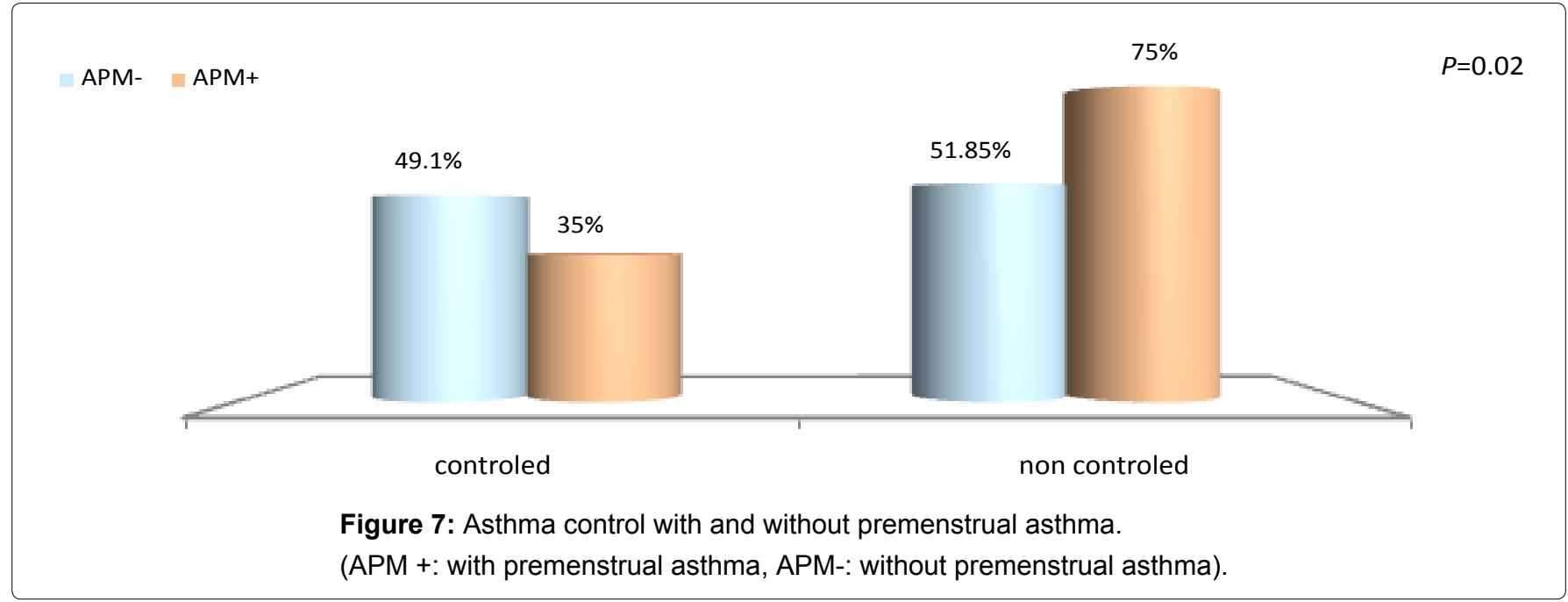

Table 2: Allergy and cutaneous tests with and without premenstrual asthma.

\begin{tabular}{|c|c|c|c|c|}
\hline & & APM - (N = 55) & $A P M+(N=40)$ & $p$ \\
\hline \multirow[b]{2}{*}{$\frac{\frac{\partial}{0}}{\frac{0}{\alpha}}$} & Family atopy & $50(90.9 \%)$ & $36(90 \%)$ & 0.88 \\
\hline & $\begin{array}{l}\text { Type of family atopy: } \\
\text {-Asthma } \\
\text {-Rhinitis } \\
\text {-Eczéma } \\
\text {-Urticaria } \\
\text {-other }\end{array}$ & $\begin{array}{l}33(60 \%) \\
15(27.3 \%) \\
2(3.6 \%) \\
0 \\
0\end{array}$ & $\begin{array}{l}23(57.5 \%) \\
11(27.5 \%) \\
1(2.5 \%) \\
0 \\
1(2.5 \%)\end{array}$ & 0.82 \\
\hline \multirow{5}{*}{ 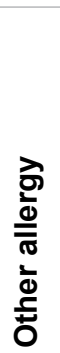 } & Rhinitis & $52(94.5 \%)$ & $40(100 \%)$ & 0.1 \\
\hline & Conjunctivitis & $37(67.3 \%)$ & $35(87.5 \%)$ & 0.02 \\
\hline & foods allergy & $4(7.3 \%)$ & $2(5 \%)$ & 0.65 \\
\hline & Médical & $6(6.3 \%)$ & $14(13.2 \%)$ & 0.10 \\
\hline & $\begin{array}{l}\text { - Pénicilline } \\
\text { - Aspirine } \\
\text { - Autre }\end{array}$ & $\begin{array}{l}4(4.2 \%) \\
1(1.81 \%) \\
3(5.45 \%)\end{array}$ & $\begin{array}{l}4(3.8 \%) \\
1(2.5 \%) \\
1(2.5 \%)\end{array}$ & 0.76 \\
\hline
\end{tabular}




\begin{tabular}{|c|c|c|c|c|}
\hline \multirow{12}{*}{ 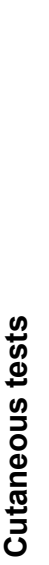 } & Positivity of prick tests & $20(36.36 \%)$ & $14(35 \%)$ & 0.68 \\
\hline & $\mathrm{Dp}$ & 14 & 12 & 0.40 \\
\hline & Df & 11 & 09 & 0.71 \\
\hline & Pollen & 3 & 3 & 0.67 \\
\hline & mold & 1 & 3 & 0.16 \\
\hline & roach & 6 & 4 & 0.85 \\
\hline & Cypress & 2 & 2 & 0.74 \\
\hline & Alternaria & 1 & 3 & 0.37 \\
\hline & Pellitory & 1 & 3 & 0.15 \\
\hline & Olivier & 1 & 4 & 0.06 \\
\hline & dog & 2 & 3 & 0.38 \\
\hline & Cat & 1 & 3 & 0.16 \\
\hline
\end{tabular}

Table 3: Risque factor of premenstrual asthma.

\begin{tabular}{|l|l|l|l|l|}
\hline & $\mathbf{N}$ & OR & IC 95\% & p \\
\hline Premenstrual syndrome & 78 & 4.21 & $1.12-15.85$ & $\mathbf{0 . 0}$ \\
\hline SDPP & 8 & 4.06 & $0.77-21.51$ & 0.0 \\
\hline Oral contraceptive & 31 & 0.81 & $0.34-1.95$ & 0.6 \\
\hline Comorbidities & 43 & 1.39 & $0.61-3.16$ & 0.4 \\
\hline gastroesophageal reflux & 6 & 1.41 & $0.27-7.35$ & 0.6 \\
\hline Conjunctivitis & 72 & 3.41 & $1.4-10.16$ & $\mathbf{0 . 0}$ \\
\hline
\end{tabular}

SDPP: Premenstrual dysphoric syndrome.

Table 4: Spirometry results of 3 menstrual cycle phases in premenstrual asthma.

\begin{tabular}{|l|l|l|l|l|}
\hline & $\begin{array}{l}\text { Follicular phase } \\
\text { Value [IC 95\%] }\end{array}$ & $\begin{array}{l}\text { Luteal phase } \\
\text { Value [IC 95\%] }\end{array}$ & $\begin{array}{l}\text { Premenstrual phase } \\
\text { Value [IC 95\%] }\end{array}$ \\
\hline VC (I) & $3.25[3.13-3.39]$ & $3.28[3.16-3.44]$ & $3.3[3.19-3.47]$ & 10.3 \\
\hline FVC (I) & $3.24[3.11-3.38]$ & $3.27[3.16-3.44]$ & $3.3[3.16-3.48]$ & 0.62 \\
\hline PEF (I/s) & $6.30[5.93-6.65]$ & $6.3[5.96-6.79]$ & $6.26[6-6.77]$ & 0.55 \\
\hline FEV1 (I) & $2.84[2.74-2.97]$ & $2.83[2.75-3]$ & $2.84[2.74-3.03]$ & 0.84 \\
\hline FEV1/VC (\%) & $87.72[85.92-89.79]$ & $86.23[84.28-88.62]$ & $85.98[83.78-88.27]$ & 0.25 \\
\hline FEF75 (I) & $5.69[5.35-6.15]$ & $5.65[5.17-6.23]$ & $5.57[5.2-6.19]$ & 0.55 \\
\hline FEF50 (I) & $3.8[3.51-4.25]$ & $3.74[3.37-4.3]$ & $3.71[3.37-4.27]$ & 0.78 \\
\hline FEF25 (I) & $1.67[1.44-1.90]$ & $1.67[1.53-1.90]$ & $1.64[1.49-1.84]$ & 0.10 \\
\hline FEF25-75 (I) & $3.38[3.1-3.75]$ & $3.25[2.93-3.72]$ & $3.24[2.93-3.68]$ & 0.55 \\
\hline
\end{tabular}

Table 5: Spirometry results of the 2 late menstrual cycle phases in premenstrual asthma.

\begin{tabular}{|l|l|l|l|}
\hline & $\begin{array}{l}\text { Lutéal Phase } \\
(\text { Value/IC 95\%) }\end{array}$ & $p$ \\
\hline VC (I) & $3.28[3.16-3.44]$ & $3.3[3.19-3.47]$ & 0.85 \\
\hline FVC (I) & $3.27[3.16-3.44]$ & $3.3[3.16-3.48]$ & 0.64 \\
\hline PEF (I/s) & $6.3[5.96-6.79]$ & $6.26[6-6.77]$ & $10^{-3}$ \\
\hline FEV1 (I) & $2.83+/-0.48 / 0.232$ & $2.84[2.74-3.03]$ & 0.61 \\
\hline FEV1/VC (\%) & $86.23[84.28-88.62]$ & $85.98[83.78-88.27]$ & 0.95 \\
\hline FEF75 (I) & $5.65[5.17-6.23]$ & $5.57[5.2-6.19]$ & 0.40 \\
\hline FEF50 (I) & $3.74[3.37-4.3]$ & $3.71[3.37-4.27]$ & 0.85 \\
\hline FEF25 (I) & $1.67[1.44-1.90]$ & $1.64[1.49-1.84]$ & 10.3 \\
\hline FEF25-75 (I) & $3.25[2.93-3.72]$ & $3.24[2.93-3.68]$ & 0.64 \\
\hline
\end{tabular}

of the menstrual cycle between groups of asthma with and without premenstrual asthma, did not find any significant difference.
The only difference found in premenstrual asthma is $C V$, which is higher during the two luteal and premenstrual phases compared to the follicular phase 
(Table 4). On the other hand, the comparison of the last two luteal and premenstrual phases only shows a significant decrease in DEP and DEM25 during the premenstrual phase compared with the luteal phase (Table 5).

This decrease in PEF was observed in 23 patients with premenstrual asthma (60\% of cases). It is estimated at $0.52 \mathrm{l} / \mathrm{s}$, which corresponds to an average decrease of $8.44 \%$ in DEP during the premenstrual phase.

\section{Discussion}

Premenstrual asthma was found in 40 patients with asthma among the 95 premenopausal patients (42.1\%). It is less common than in the Vega series [5] which published the highest rate of $52.54 \%$. The incidence of premenstrual asthma is higher in women younger than $35(32.5 \%)$, but tends to decrease with age. The average age is 34.78 years almost identical to that reported by SABRY [6] and RAO [7]. In contrast, Shames and Thornton found a higher incidence of premenstrual asthma in peri-menopausal women $[1,8]$.

The symptoms of premenstrual asthma are variable. In our series, premenstrual asthma was expressed only by respiratory discomfort in $85 \%$ of cases. This result is close to that of AGARWAL who studied the different symptoms in premenstrual asthma. He found dyspnea in $96 \%$ with wheezing in $52 \%$ of cases, chest tightness in $43 \%$ of cases, cough in $39 \%$ of cases and sputum in $13 \%$ of cases [9].

\section{-Severity of asthma in premenstrual asthma}

Most patients with premenstrual asthma have moderate asthma in $52.5 \%$ of cases, or mild in $35 \%$ of cases. There was no high incidence of severe asthma in asthmatics with premenstrual asthma (7.5\%). The same finding was reported by VEGA [5]. In contrast, Rao reported severe asthma in $50 \%$ of women with premenstrual asthma [7]. Several other studies have found a link between premenstrual asthma and the severity of asthma $[6,8,10,11]$.

In addition, premenstrual syndrome in our series is present in almost all patients with premenstrual asthma (92.5\%). The frequency of premenstrual syndrome observed in our series is close to that of Dorhofer [12] but higher than that reported by ENSOM [13] and Vega [14]. Skrzypulec found a low incidence of this syndrome in adolescent asthmatics (20\%) compared with non-asthmatics (46.67\%) [15].

In our series, premenstrual syndrome is statistically significantly associated with uncontrolled asthma (85.2\%). This frequent association suggests a common mechanism of occurrence of these two entities including the psychic component which has been frequently found in the literature as a factor associated with premenstrual asthma [12], as is premenstrual syndrome [16]. Although the psychic component was not studied in this work, the irritability marking the premenstrual syndrome in $87.5 \%$ of patients could cause a suspicion of a psychic cause in the occurrence of premenstrual asthma.

The symptoms of premenstrual asthma are accompanied by a significant increase in VC from the follicular phase to the premenstrual phase. Knowing that progesterone increases during the luteal phase and reaches its maximum in pre-menstruation, the increase in ventilation represented by an increase in VC is most likely related to the increase of this hormone [17].

On the other hand, the analysis of the last two phases of the cycle during which patients are symptomatic, found low levels of PEF in $60 \%$ of cases. In the literature, low levels of DEP in pre-menstruation were reported by OGUZULGEN [18], KAUR [19] and MURPHY [20] while ARORA found significantly elevated flow and volume values during the luteal phase, compared to the premenstrual phase [21].

This suggests that the anti-inflammatory effect of estradiol at normal levels [22] can become pro-inflammatory at high levels $[23,24]$. These elevated levels observed during the luteal and even premenstrual phase may be responsible for bronchial obstruction marked by a decrease in PEF during premenstrual asthma.

\section{Conclusion}

Variations in the symptoms of asthma and respiratory function during the menstrual cycle strongly suggest the role of sex hormones on the bronchial tree. Although the mechanism of action of the sex hormones on the woman's respiratory system is unclear, premenstrual asthma, which is felt subjectively in $42.1 \%$ of our patients, is of particular interest, especially since the prevalence of asthma is increasing in the world.

\section{References}

1. Shames RS, Heilbron DC, Janson SL, Kishiyama JL, Au DS, et al. (1998) Clinical differences Among Women with and Without Self-Reported Perimenstrual. Ann Allergy Asthma Immunol 81: 65-72.

2. Magadle R, Berar-Yanay N, Weiner $P$ (2001) Long-acting bronchodilators in premenstrual exacerbation of asthma. Respir Med 95: 740-743.

3. Pereira Vega A, Sanchez Ramos JL, Maldonado Perez JA, Alvarez Gutierrez FJ, Ignacio Garcia JM, et al. (2010) Variability in the prevalence of premenstrual asthma. Eur Respir J 35: 980-986.

4. Ensom MH, Chong FE, Ensom (1999) Premenstrual symptoms in women with premenstrual asthma. Pharmacotherapy 19: 374-382.

5. Pereira-Vega A, Sanchez Ramos JL, Vazquez Oliva R, Maldonado Perez JA, Alwakil Olbah M, et al. (2012) Premenstrual asthma and female sex hormones. J Investig Allergol Clin Immunol 22: 437-439.

6. Sabry EY (2011) Relation of perimenstrual asthma with disease severity and other allergic co-morbidities-the first report of perimenstrual asthma prevalence in Saudi Arabia. Allergol Immunopathol (Madr) 39: 23-26. 
7. Rao CK, Moore CG, Bleecker E, Busse WW, Calhoun W, et al. (2013) Characteristics of perimenstrual asthma and its relation to asthma severity and control: Data from the Severe Asthma Research Program. Chest 143: 984-992.

8. Thornton J, Lewis J, Lebrun CM, Licskai CJ (2012) Clinical characteristics of women with menstrual-linked asthma. Respir Med 106: 1236-1243.

9. Agarwal AK, Shah A (1995) Menstrual linked asthma. J Asthma 34: 539-545.

10. Brenner BE, Holmes TM, Mazal B, Camargo CA (2005) Relation between phase of the menstrual cycle and asthma presentations in the emergency department. Thorax 60: 806-809.

11. Zimmerman JL, Woodruff PG, Clark S, Camargo CA (2000) Relation between phase of menstrual cycle and emergency department visits for acute asthma. Am J Respir Crit Care Med 162: 512-515.

12. Dorhofer DM, Sigmon ST (2002) Physiological and psychological reactivity in women with asthma : The effects of anxiety and menstrual cycle phase 1. Behav Res Ther 40: 3-17.

13. Chong E, Ensom MHH (2000) Peak expiratory flow rate and premenstrual symptoms in healthy nonasthmatic women. Pharmacotherapy 20: 1409-1416.

14. Pereira-Vega A, Sánchez JL, Gil FL, Maldonado J a, Bravo JM, et al. (2010) Premenstrual asthma and symptoms related to premenstrual syndrome. J Asthma 47: 835-840.

15. Skrzypulec V, Doniec Z, Drosdzol A, Nowosielski K, Pawlińska-Chmara R (2007) The influence of bronchial asthma on premenstrual syndrome prevalence among girls. J Physiol Pharmacol. 58: 639-646.
16. Piccand L (2012) Du syndrome prémenstruel au trouble dysphorique prémenstruel . Une reconfiguration des représentations sur la vulnérabilité des femmes. Du syndrome prémenstruel au trouble dysphorique prémenstruel 1-11.

17. Saaresranta T, Polo O (2002) Hormones and Breathing. Chest, The American College of Chest Physicians 122: 2165-2182.

18. Oguzulgen IK, Turktas H, Erbas D (2002) Airway inflammation in premenstrual asthma. J Asthma 39: 517522.

19. Kaur S, Behera D (2010) Pre and post menstrual peak flow rates and symptoms amongst patients with bronchial asthma. J Assoc Physicians India 58: 331.

20. Murphy VE, Gibson PG (2008) Premenstrual asthma: Prevalence, cycle-to-cycle variability and relationship to oral contraceptive use and menstrual symptoms. J Asthma 45: 696-704.

21. Arora D, Kaur P, Arora M, Gupta U (2011) Influence of menstrual cycle on lung functions of asthmatic females. Indian J Fundam Appl Life Sci 1: 2231-634562.

22. Straub RH (2007) The Complex Role of Estrogens in Inflammation. Endocr Rev 28: 521-574.

23. Paula A, Oliveira L De, Domingos HV, Cavriani G, Damazo AS, et al. (2007) Cellular recruitment and cytokine generation in a rat model of allergic lung inflammation are differentially modulated by progesterone and estradiol. Am J Physiol Cell Physiol 293: 1120-1128.

24. L Ackeman (2006) Sex hormones and the genesis of autommunity. Arch Dermatol 142: 371-376. 